\title{
The Relationships between In- and Out-group Perceptions and Evaluations, and the Social Identity Dimensions of Covered/Uncovered Female Students in Turkey
}

\author{
M. Ersin Kuşdil \\ Uludag University \\ mekusdil@uludag.edu.tr \\ Nahide Günbay \\ Bursa, Turkey \\ Nahide16@gmail.com
}

Doi:10.5901/mjss.2014.v5n23p1632

\begin{abstract}
Allowing female students to enter universities in headscarves has long been a major goal of all Islamist political parties, whereas secularists have regarded this issue as a serious fundamentalist threat to the Turkish Republic. This study of the head coverage issue was conducted in 2006, taking a sample of 100 female university students at Uludag University in Bursa Turkey, where around half of the female students wear headscarves. Data was collected on the in-group/out-group perceptions and evaluations of both covered and uncovered students using structured and semi-structured social identity inventories, and the gathered data was examined in line with the predictions of Tajfel and Turner's social identity theory and Verkuyten's identity dimensions of "being," "feeling," "doing" and "knowing". The results showed that, although the perceptions and evaluations of students with and without headscarves pointed to an in-group/out-group distinction, there were striking similarities between the identity dimensions of the two groups in several social categories.
\end{abstract}

Keywords: head covering, headscarf, veiling, intergroup conflict, social identity theory

\section{Introduction}

The primary aim of this study is to examine the in-group/out-group evaluations of covered/uncovered students in the light of the predictions stated in the Social Identity Theory (SIT) of Tajfel and Turner. The SIT framework has been adapted to allow an understanding of the nature of the relationship between students with and without headscarves ${ }^{1}$ by focusing on their perceptions of their in- and out-groups. In order to account for the possibility that these groups of students share similarities in their worldviews, we also contrasted these groups' perceptions towards several social categories such as gender, religion, family, age, in-group and education.

\subsection{A Short History of the Headscarf Issue}

Turkey is a Muslim-majority country, with approximately ninety-nine percent of the population following Islam. However, among the 52 Muslim-majority nation-states worldwide, Turkey is one of only two (the other being Senegal) whose constitution prescribes secularism (Wing \& Varol, 2007). Turkey's history of secularism began with the founding of the Republic in 1923, when laws were enacted aimed at protecting the secular spirit of the modern republic, including legislation requiring citizens to follow a certain dress code that forbade some forms of dress for both men and women (see Kalaycıoğlu, 2005; Wing \& Varol, 2007). The modernization efforts focused mainly on "the emancipation of women" (Göle, 1996) by means of several unprecedented legislative and governmental practices that included positive discrimination in access to education and the advent of full suffrage in 1934, as well as the banning of the veil. All of these steps were aimed at increasing the participation of women in public life, which was seen as the most important sign of modernization. The image of the "ideal Turkish woman" of the era was promoted as a professionally and politically

1 The covering up of the face and/or hair for religious reasons can take many forms, however the extent of covering lies outside the scope of this paper. For reasons of clarity, the terms "headscarf" or "covered" will be used in this paper to denote all forms of coverage for religious reasons. 
active person who was knowledgeable of her rights and knew how to use them in the new republic (Gökarıksel, 2009, p. 662). As the "honor and modesty of woman" had always been associated with the practice of veiling in Turkish society, attempts were made to resolve the problems that arose out of the search for the moral foundations of this new "ideal" with a secularist moral framework that legitimized the presence of women in public spaces as "asexualized and defeminized subjects" who devoted themselves to the new nation's progress (Kadıoğlu, 1998; cited in Gökarıksel, 2009, p. 663). The issue of modesty in women, however, remained paradoxical, since and is considered today as the point of convergence between the secular and Islamic lifestyles. As a result of this, the practices of veiling/unveiling "the body as a religious/secular space, or as a space where these forces intersect and compete" (Gökarıksel, 2009, p. 669) have always been at the core of the conflict between Islamists and secularists.

The dress codes of the new republic have been followed strictly by civil servants in all governmental institutions; but in contrast, the code is overlooked by much of society, aside from in such public places such as university classes, military institutions and courts. Among these public spheres, universities have become the symbolic battleground for both Islamists and secularists in seeking to defend their ideologies. The agenda of all Islamist parties over the last three decades has been to allow head coverings in universities, however secularists have regarded this issue as a serious fundamentalist threat to the very heart of the modern Turkish Republic, while Islamists tend to discuss the issue in terms of universal human rights. The tension between "secular versus Sunni revivalist kulturkampfs" (Kalaycıoğlu, 2005, p. 236) has escalated gradually after two landslide victories by the major Islamist party in the general elections, and the issue reached a peak after Parliament passed a proposal for a constitutional change in 2008 that abolished the banning of headscarves for university students. Soon after passing the legislation, the Constitutional Court rejected the new law as a threat to the secular core of the Constitution of the Turkish Republic. In the meantime, many observers of the several large-scale protests staged by women-dominated masses against the constitutional change suggested that the conflict was a sign of a dangerous rift within Turkish society.

The above-mentioned observations are supported by the robust findings of a number of political scientists. Based on the findings of two mass surveys of nationally representative samples in 2002 and 2003, Kalaycioğlu (2005) showed that attitudes toward the headscarf issue among Turkey's voting age population were closely related to attitudes regarding religiosity and political Islam. Although political Islam was not the only source of such attitudes, the findings clearly showed that the headscarf issue was religious in nature, and related to the meaning and practice of secularism in Turkey. These findings are consistent with the suggestions that veiling in general is a medium through which the cultivation of the piety and modesty associated with Islam in everyday practices is realized (Gökarıksel, 2009, p. 661).

Empirical social psychological studies on the headscarf issue are rare, and those that do exist fall short of defining the social perceptual aspects of this conflict. One exception is the empirical study conducted by Hortaçsu (2000), which investigated the social relations between covered and uncovered university students in 1996 and 1998. Using SIT, Hortaçsu categorized the relations between these groups as minority (covered students) and majority (uncovered students). The results of the study showed that, although the covered students expressed a lower tolerance for outgroups than those that were uncovered in 1996, this tendency was reversed in 1998. The contact conditions expressed by the uncovered participants were more negative in 1998 than in 1996, whereas the covered participants' reports on the contact conditions did not change significantly over the same period. Hortaçsu explained the change in the majority's reports as being a consequence of the supportive normative climate for discrimination towards covered women and the majority's reactions to the increasing salience and success of the Islamist party from 1996 to 1998. These findings are a clear indication that a social psychological analysis of the headscarf conflict must take into account the effects of the social and political context on people's perceptions regarding the issue.

\subsection{The Present Study}

The above-mentioned findings show that the relationships between students with and without headscarves are affected mainly by attitudes regarding traditions, religiosity and political Islam, and the social and political context within people's perceptions about the headscarf issue. However, existing literature has to date been quite limited in showing to what extent the worldviews of these groups differ from each other. For example, through a documentary analysis and in-depth interviews with pro-secular feminist and Islamist women's groups in Turkey, Aldikacti-Marshall (2005) reported that these groups expressed quite similar complaints regarding the issue of headscarf and work. The limitations encountered in literature would seem to be a result of focusing on only the prejudice that these groups exhibit towards each other. Although it has become the most effective and widely used theory among the new approaches in the area of intergroup relations (see, Brown 2000; Huddy 2004; Dumont and Louw 2007), applying SIT to this issue without considering the elusive similarities between the rival camps is likely to lead to the same problem. 
Drawing on the ideas of Phinney (1990), Verkuyten (2005) suggests that social (or ethnic) identities may contain some contradictory elements, and so can only be analyzed satisfactorily by decomposing them into four main dimensions: "Being" (self-labeling; e.g., ethnic origin, natural parents, visible characteristics, etc.); "knowing" (information about identity; e.g., group beliefs, culture, history, entitlements, norms, etc.); "feeling" (affective experiences; importance of identity, evaluation, commitment, etc.); and "doing" (behavioral component; participation in group activities, clothes, food, etc.). Verkuyten adds that there may be complex and unique relationships among these dimensions, and that any loose connections between them are quite possible and tolerable. By drawing upon the findings of his research of several ethnic groups in the Netherlands, Verkuyten (2005) concludes that such a conceptualization seems functional for the study of ethnic identities, especially in multicultural societies and different generations of ethnic groups. Although he acknowledges the unique contributions of SIT in understanding the importance of a sociopolitical context on group behavior, Verkuyten insists that approaching the ethnic identity issue with the help of these four dimensions will widen ones' perspective when attempting to understand the complex nature of intergroup relations.

In the present study, the primary aim was to ascertain whether young women with and without headscarves formed two distinct identity groups. Using Tajel and Turner's SIT as a theoretical framework in a study of the social perceptual aspects of the relationships between these groups of university students, three basic concepts of SIT were focused upon in the search for the in-group/out-group distinctions within the group: (a) in-group identification, (b) in-group bias, and (c) the use of the principle of metacontrast in evaluating the in-group prototypes (see, Hogg, 2006).

Tajfel (1978, p. 63; see also, Tajfel, 1982) defines social identity as "part of an individual's self-concept that derives from his knowledge of his membership of a social group (or groups), together with the value and emotional significance attached to that membership." Moreover, social identity researchers conceptualize social identity as "the process that transforms interpersonal into intergroup behavior" (Turner, 1999, p. 11). For SIT theoreticians, individuals internalize the group membership identity as their own, and display high levels of identification with the in-group (Tajfel \& Turner, 1979). For SIT, the in-group bias leads inevitably to social categorization and high identification with the in-group, with individuals tending to favor the in-group over the out-group in both symbolic as well as material terms. SIT theoreticians expect this tendency to be evident in the individual's use of the in-group prototype, being "a fuzzy set of attributes (perceptions, attitudes, feelings and behaviors) that are related to one another in a meaningful way" (Hogg, 2006, p. 118). According to Hogg (2006), prototypes describe rather ideal, and even hypothetical, in-group members, and are influenced directly by the principle of metacontrast, which is a cognitive tendency to exaggerate "the ratio of perceived intergroup differences to intragroup differences, and thus accentuate similarities within groups and differences between groups" ( $p$. 118).

Drawing upon the above-mentioned conceptualizations, the intention in this study is to compare the identification levels of students with or without headscarves with in-groups (being a member of a group of students with or without headscarves) and with religion. Any significant difference in the levels of identification with in-groups should be considered as a sign of an intergroup relation. Also of interest is a comparison between the levels of identification with the religion category, as this would show whether the issue of identification with Islamic society in general occupies a pivotal position in the headscarf issue.

Moreover, how similar the individual members of these groups see themselves to the members of other groups will be examined by asking participants to list the attributes of their members of the in- and out-groups. Additionally, the participants will also be asked to rate to what extent the attributes they have provided describe their own personality. As mentioned above, SIT suggests that any significant difference in these perceptions should be considered as a sign of an intergroup differentiation, in that any identification with a social identity should lead individuals to perceive in-group members as similar to themselves, while the level of the perceived similarity with out-group members would decrease. Whether the participants apply the metacontrast principle or not will be examined from the values they assign to the attributes they have provided when describing the in- and out-group members. Any significant difference between the value assignments given to the in- and out group members will prove that the principle of metacontrast is in effect, as would be expected in an intergroup context.

According to Tajfel and Turner (1979), social identities are used by individuals in the constant social comparisons they make in their daily lives. However, as in-groups do not compare themselves with all existing social categories, an appropriate comparison group is chosen that considers such factors as similarity, closeness and situational salience (Tajfel \& Turner, 1979). Although the variability in choosing a comparison group "is relatively modest because of the anchoring effect of enduring and highly accessible representations of important groups we belong to but may be more dramatic in new groups or groups that we know less about" (Hogg, 2006, p. 118), change is possible. It is plausible to assert that any change in the social context will not take place in a chaotic way, and that the similarities or differences in the groups' worldviews, beliefs or ideologies are important in the selection of a new comparison group. Accordingly, the 
final aim in this study is to see to what extent the attitudes of participants with and without headscarves towards a number of social categories in Turkish society differ from each other. To this end, the "being," "feeling" and "knowing" dimensions of Verkuyten's model are applied to delineate the basic elements of the social identities of these groups.

To examine the "being" dimension, the participants' levels of identification with social categories of gender, religion, family, age, in-group and education will be analyzed, together with the identity descriptions that reveal their relatively stable identity styles (personal, social, or collective). In this way, the most salient elements in the identity constructions of both the covered and uncovered students will be identified. For the "feeling" dimension, an examination will be made of to what extent the members of these two groups differ in their perceptions of similarity to the categories of gender, religion, family, age and education. Finally, the conceptions of students with and without headscarves regarding the "woman ideal" will be compared in an examination of the "knowing" dimension. These conceptions have been selected as a viable means of examining the identity dimension, based on the assumption that they reflect the prevalent normative expectations of both groups of students, and this variable will also help us to see whether these groups promote inherently different "moral frameworks" in their approach to the issue.

\section{Method}

\subsection{Participants}

The sample comprised 100 female students from various departments of Uludag University in Bursa, Turkey, around half of which wore a headscarf as part of a religious affiliation. The average number of years of university attendance for the covered participants $(M=1.83 ; S D=.96)$ was not significantly different from that of the uncovered participants $(M=1.79$; $S D=.94 ; t(2,81)=0.165, p>.05)$.

\subsection{Procedure}

The study was conducted during the spring term of 2006, when participants for the study were approached on the university campus using the convenience sampling technique. Although the best practice would have been to employ two assistants for the data collection phase, one covered and the other uncovered, due to limitations, only the second author of the paper, who wore a headscarf, was engaged in this phase. After the confidentiality and anonymity of responses were guaranteed, the participants filled out the questionnaire in their spare time and returned them to the researchers. The average completion time of the questionnaire was about 45 minutes. Students participated in the survey voluntarily, and received no compensation for their participation.

\subsection{Instruments}

\subsubsection{Social Identity Inventory}

To garner information about participants' perceptions of several groups within their social environments, Bilgin's (1995) Turkish translation of Zavalloni's (1984; cited in Bilgin, 1995) Social Identity Inventory was adopted. This inventory provides valuable qualitative and quantitative information for an analysis of intergroup relations and perceptions. Each participant completed the inventory in four steps:

1. The participant described seventeen social categories (we, the women; women in general; men in general; we, the devout people; devout people in general; we, the women with headscarves /without headscarves [ingroup]; women with headscarves/without headscarves in general [in-group in general]; them, the women with headscarves/without headscarves [out-group]; we, the young people; young people in general; my family; families in general; we, the university students; university students in general; my friends; ideal woman; and people I do not like) with three adjectives or short sentences. The participant selected her "in-group" and "outgroup" by deleting the inappropriate options in the category statements "We, the women with headscarves/without headscarves" and "Women with headscarves/without headscarves in general".

2. Each participant, returning to their descriptions, rated the extent to which she believed each of these attributes (adjectives or short descriptions) described herself, using a three-point scale ranging from 1 (not suitable for my personality) to 3 (completely suitable for my personality). Prior to the analyses, the average of the participant's ratings for each of the seventeen social categories were identified, and were named as similarityto-self ratings, specifying the extent to which the participant thought the attributes she had assigned to a 
category reflected also her own personality.

3. The participant rated the value of her attributes by assigning a positive (1), a negative ( -1$)$, or neutral $(0)$ sign to each of them. Before the analyses, the average of the participant's ratings for each of the seventeen social categories were identified, and were named the value ratings, specifying the extent to which the participant saw the attributes she provided for a category as valuable and desirable.

4. Finally, the participant rated the extent to which she identified with each of the six basic social groups (gender, religion, age, family, education and in-group [women with headscarves/without headscarves]) using a sevenpoint scale, ranging from 1 (I would never want to be a member of this group) to 7 (I would very much want to be a member of this group). These six scores were named as the identification ratings.

\subsubsection{Identity Scale}

Coşkun's (2004) Turkish translation of Cheek and Briggs' (1982) Identity Scale was used to assess the relative weight each participant attributed to personal, social and collective identities. The personal identity subscale of this instrument included ten items for measuring an individual's personal values, moral standards, aspirations, coping styles and level of self-esteem. The second subscale, social identity, is composed of seven items that measure the individual's conception of the impression she thinks she makes on other people, based on her physical attractiveness and social behavior. Lastly, the collective identity scale is composed of eight items and assesses the extent of an individual's positive feelings regarding her membership of social groups based on family, religion, ethnicity, politics and nation. Each item in the instrument was presented to the participants together with a 5-point scale ranging from 1 (unimportant in defining myself) to 5 (always important in defining myself). The estimates of internal consistency for personal, social, and collective identity subscales were all at acceptable levels, measuring (.78), (.82) and (.69) respectively.

\section{Results}

\subsection{Results Regarding the SIT's Basic Concepts}

A comparison was made of the identification ratings that the participants from either group had assigned to the six social categories (gender, religion, age, family, education and in-group), i.e., the extent to which they felt these categories mattered in their social identifications. The results of one-way ANOVAs (see Table 1) revealed that the covered students' identification ratings of the in-group (Cohen's $d=1.3987$ ) and religion (Cohen's $d=0.6476$ ) categories were significantly higher than those provided by the students without headscarves. The high level of identification with the religion group exhibited by the members of the covered group shows that the identity of these students takes its roots from religion.

On the other hand, there was no significant difference between the groups' similarity-to-self ratings regarding their out-groups (i.e., covered students for participants without headscarves; and women without headscarves for covered participants) (see Table 2; Cohen's $d=0.2849$ ), indicating that the participants with and without headscarves saw outgroup members as similar to themselves. A similar picture arises from the results of the one-way ANOVA comparison of the covered and uncovered students' value ratings of the attributes they provided for different social categories. Although the covered group's value ratings of the uncovered group of students (i.e., their out-group) were more negative than the uncovered group's ratings of their out-group (i.e., covered students), the difference was not statistically significant (see Table 2; Cohen's $d=0.3946$ ).

To examine the differences between the evaluations directed at in- and out-groups by the covered and uncovered participants, two paired-sample $t$ - tests were conducted for the similarity-to-self ratings and value ratings of each group. The overall results of these comparisons revealed that the participants' similarity-to-self ratings regarding their in-group were not significantly different from the ratings they provided to describe the out-group (uncovered participants' rating for their in-group: $M=2.55, S D=.61$; uncovered participants ratings for their out-group: $M=2.34, S D=.56 ; t(48)=1.743, p$ $>.05$; Cohen's $d=0.5032$; head covered participants' ratings for their in-group $M=2.44, S D=.54$; covered participants' ratings the for their out-group $M=2.46, S D=.48 ; t(48)=.381, p>.05$; Cohen's $d=0.11$ ). These results offer an indication that the participants did not consider their out-groups to be so different from themselves. 
Table 1: One-Way ANOVA Comparisons of Participants' Personal, Social and Collective Identity Scores and Identification Ratings of Different Group Memberships

\begin{tabular}{|l|c|c|c|}
\hline & Uncovered $(\mathrm{n}=48)$ & Covered $(\mathrm{n}=48)$ & \\
\hline & Mean $(\mathrm{SD})$ & Mean $(S D)$ & $\mathrm{F}$ \\
\hline Identity types: Personal & $4.35(.48)$ & $4.19(.51)$ & 2.512 \\
\hline Social & $3.16(.75)$ & $3.03(.80)$ & .686 \\
\hline Collective & $3.44(.72)$ & $3.80(.51)$ & $8.156^{\star}$ \\
\hline Groups: Gender & $4.02(.91)$ & $3.71(.94)$ & 2.723 \\
\hline Age & $4.19(.73)$ & $4.19(.79)$ & .000 \\
\hline Family & $4.60(.68)$ & $4.52(.65)$ & .378 \\
\hline Religion & $4.38(.79)$ & $4.81(.49)$ & $10.646^{\star \star}$ \\
\hline In-group & $3.31(1.06)$ & $4.60(.76)$ & $47.172^{\star}$ \\
\hline Education & $4.23(.81)$ & $4.21(.87)$ & .015 \\
\hline
\end{tabular}

${ }^{*} p<.001 ;{ }^{*} p<.0001$

That said, the value ratings that the participants assigned to the attributions of their in-group were significantly higher than those given to the attributions of the out-group (uncovered participants' value ratings for their in-group: $M=.62, S D=.61$; uncovered participants' value ratings for their out-group: $M=.21, S D=.63 ; t(49)=3.717, p<.001$; Cohen's $d=1.062$; covered participants' value ratings for their in-group: $M=.21, S D=.63$; covered participants' value ratings for their outgroup: $M=-.02, S D=.74 ; t(48)=5.215, p<.0001$; Cohen's $d=1.5054)$. These findings indicate that the participants in the study tended to see members of their respective in-groups as having more positive characteristics than the members of the out-group.

Although the paired comparisons of the in- and out-group evaluations by participants with and without headscarves provided a valuable insight into understanding the nature of the in-group bias of each group, the question of which group exhibited a greater bias, i.e., the application of the principle of metacontrast, remained unanswered. To answer this question, two new variables were formed for each participant by subtracting their out-group evaluation scores from those of their in-group evaluations. Subsequently, one of the new scores was used to assess the difference between the similarity-to-self ratings directed at the in- and out-groups, while the other score was used to specify the difference between the value ratings of the participants' descriptions in evaluating their in- and out-groups. The results of the two ttests showed that the level of difference between the similarity-to-self ratings of the attributes appointed to the in- and outgroups (participants without headscarves: $M=.21, S D=.81$; covered participants: $M=-.04, S D=.69$ ) and the level of difference between the values assigned for the attributions of in- and out-groups (participants without headscarves: $M=$ $.46, S D=.87$; covered participants: $M=.71, S D=.95$ ) were not significantly different between the covered and uncovered groups (for the difference scores of similarity-to-self ratings: $t(96)=1.574, p>.05$; Cohen's $d=0.3213$; for the difference scores of value ratings: $t(97)=1.387, p>.05$; Cohen's $d=0.2817$ ). In other words, both groups exhibited an equal in-group bias. In order to determine the most important variables for predicting the variance within the participant groups based on their evaluations of in- and out-groups, two regression analyses were performed. The two "difference" variables described above were subjected to multiple regression analyses in which the scores for the three identity styles (personal, social and collective) and the identification ratings of the six basic social

Table 2: One-Way ANOVA Comparisons of Head Covered and Head Uncovered Students' Similarity-to-Self Ratings and Value Ratings of the Descriptions they Provided for Different Social Categories

\begin{tabular}{|l|c|c|c|c|c|c|}
\hline & \multicolumn{2}{|c|}{ Similarity-to-Self Ratings } & & \multicolumn{2}{|c|}{ Value Ratings } & \\
\hline & $\begin{array}{c}\text { Uncovered } \\
(n=47)\end{array}$ & $\begin{array}{c}\text { Covered } \\
(n=43)\end{array}$ & & $\begin{array}{c}\text { Uncovered } \\
(n=47)\end{array}$ & $\begin{array}{c}\text { Covered } \\
(n=43)\end{array}$ & \\
\hline & $M e a n(S D)$ & Mean (SD) & $F$ & $M e a n(S D)$ & Mean (SD) & $F$ \\
\hline We, the women & $2.03(.46)$ & $2.06(.39)$ & .098 & $.41(.49)$ & $.44(.49)$ & .086 \\
\hline Women in general & $2.50(.44)$ & $2.31(.43)$ & $5.020^{*}$ & $.16(.61)$ & $.09(.68)$ & .214 \\
\hline Men in general & $2.33(.48)$ & $2.47(.52)$ & 2.011 & $-.13(.58)$ & $-.05(.69)$ & .432 \\
\hline We, the Devout People & $2.60(.47)$ & $2.66(.45)$ & .380 & $.65(.59)$ & $.93(.25)$ & $8.593^{*}$ \\
\hline Devout People in general & $2.47(.57)$ & $2.49(.55)$ & .032 & $.46(.71)$ & $.40(.81)$ & .169 \\
\hline In-group (We, the covered/uncovered women) & $2.57(.59)$ & $2.47(.52)$ & .710 & $.63(.59)$ & $.58(.60)$ & .155 \\
\hline In-group in general (covered/uncovered women) & $2.41(.57)$ & $2.52(.46)$ & 1.100 & $.44(.59)$ & $.28(.67)$ & 1.537 \\
\hline
\end{tabular}




\begin{tabular}{|l|c|c|c|c|c|c|}
\hline Out-group (covered/ uncovered women) & $2.36(.58)$ & $2.50(.46)$ & 1.823 & $.19(.63)$ & $-.08(.74)$ & 3.496 \\
\hline We, the young people & $2.36(.46)$ & $2.49(.43)$ & 2.100 & $.32(.68)$ & $.57(.60)$ & 3.195 \\
\hline Young people in general & $2.32(.55)$ & $2.51(.49)$ & 3.502 & $-.05(.65)$ & $-.25(.72)$ & 1.953 \\
\hline My family & $2.71(.44)$ & $2.69(.46)$ & .048 & $.82(.45)$ & $.79(.40)$ & .077 \\
\hline Families in general & $2.56(.61)$ & $2.65(.51)$ & .709 & $.77(.52)$ & $.80(.48)$ & .058 \\
\hline We, the university students & $2.38(.47)$ & $2.43(.51)$ & .226 & $.38(.71)$ & $.47(.62)$ & .341 \\
\hline University students in general & $2.42(.49)$ & $2.47(.48)$ & .303 & $.16(.72)$ & $-.25(.71)$ & $7.443^{\star}$ \\
\hline My friends & $2.64(.51)$ & $2.69(.44)$ & .318 & $.88(.28)$ & $.78(.47)$ & 1.445 \\
\hline Ideal woman & $2.43(.59)$ & $2.65(.43)$ & $4.229^{*}$ & $.90(.24)$ & $.96(.15)$ & 2.021 \\
\hline People I do not like & $2.30(.72)$ & $2.57(.68)$ & 3.801 & $-.47(.68)$ & $-.60(.64)$ & .862 \\
\hline
\end{tabular}

$* p<.05$

categories (gender, religion, age, family, education and in-group) were used as independent variables. The results revealed that none of the three identity variables predicted a significant variance in these two dependent variables, although it could be understood that the personal style in defining one's identity is not an effective factor in explaining the in-group bias. As for the identification variables, only the identification with the in-group score appeared to be a significant predictor of the difference score for the value ratings $(F[9.96]=1.135, p>.05 ; \beta=.25, p<.05)$. As predicted by SIT, as a member's identification with her in-group increases, the likelihood that she will exhibit an in-group bias in her evaluations of in- and out-group members also increases. However, neither the identification with the in-group variable, nor the other five identification variables was effective in predicting a significant variance in the difference scores for similarity-to-self ratings. In general, these findings are in line with the SIT prediction, that the positive and negative evaluations of the members of out-groups are the function of a group dynamic (a high or low identification) rather than a person's relatively stable identity style.

\subsection{Results Related to the "Being" Dimension}

A discriminant analysis was carried out to determine which of the three identity styles (personal, social and collective) and levels of identification within the six social categories (gender, religion, age, family, education and in-group) contributed most to predicting the participants' membership of the covered or uncovered group. As seen in Table 3, the results of the discriminant analysis showed a fairly high prediction rate, and based on the responses to these variables, the analysis correctly predicted the group membership of ninety-six participants by nearly 78 percent. When the variables that predict the probability of a participant belonging definitively to one of the two groups are taken into account, the composition of these groupings does not appear arbitrary; with the variables of "identification with religion," "identification with the ingroup" and "collective identity" being among the most powerful predictors for determining membership of the covered group. In contrast, the variables "identification with gender group" and "personal identity" were the most crucial variables in predicting the probability of membership of the uncovered group.

Table 3: Discriminant Analysis of the Scores of Covered/Uncovered Student Groups on Personal, Social, and Collective Identities and for the Identification Ratings of Gender, Religion, Age, Family, Education and In-group Categories

\begin{tabular}{|c|c|c|c|c|}
\hline Function & Eigen value & \% of Variance & Cumulative & Canonical Correlation \\
\hline 1 & 0.811 & 100.0 & 100.0 & 0.669 \\
\hline Test of Functions & & Wilk's Lambda & & Significance \\
\hline 1 & & .552 & & 0.0001 \\
\hline & Structure Matrix & Function 1 & & \\
\hline & In-group & .786 & & \\
\hline & Religion & .374 & & \\
\hline & Collective Identity & .327 & & \\
\hline & Gender & -.189 & & \\
\hline & Personal Identity & -.182 & & \\
\hline & Social Identity & -.095 & & \\
\hline & Family & -.070 & & \\
\hline & Education & -.014 & & \\
\hline & Age & .000 & & \\
\hline & Number of Observations: & 96 & & \\
\hline & Correctly Predicted: & $78.1 \%$ & & \\
\hline
\end{tabular}




\subsection{Results Related to the "Feeling" and "Knowing" Dimensions}

A one-way ANOVA was used to compare the covered and uncovered participants' similarity-to-self ratings of the defined attributes (adjectives or short descriptive phrases) of the different social categories. The results showed that only the similarity-to-self ratings for the "women in general" category was statistically different for the student groups with and without headscarves (see Table 2; Cohen's $d=0.4728$ ), with the uncovered students tending to rate the attributes they provided for the "women in general" category as more suitable for defining themselves than did the covered participants. In other words, compared to the covered students, those without headscarves saw "women in general" as being more similar to themselves. Another significant difference was found in "the ideal woman" category (the marker of the "knowing" dimension). In this case, the covered students found their defined attributes of this category as being more suitable for defining their personalities than did the uncovered participants (see Table 2; Cohen's $d=0.4340$ ).

The covered participants, on the other hand, assigned more positive values to the attributes they provided regarding "we, the devout people" than did the uncovered students (see Table 2; Cohen's $d=0.6186$ ). However, values assigned by the covered students for the attributes of the "university students in general" category were negative (see Table 2; Cohen's $d=0.5757$ ). This finding showed that the covered participants did not consider their fellow students as being in possession of desirable personality attributes.

\section{Discussion}

The results of the analyses regarding the basic concepts of SIT revealed that the identification levels of covered students with their in-group were significantly higher than those of the uncovered students with their in-group. Initially, the findings about uncovered students having lower levels of in-group identification than covered students may indicate an absence of an in- and out-group differentiation. However, further analysis reveals that a differentiation may be present, indicated by the participants' in-group/out-group evaluations, which point to the perceptual aspect of an in-group bias as a basic characteristic of intergroup behavior found in SIT. Although the "similarity-to-self" ratings of the attributes ascribed by participants to their in- and out-groups bore no evidence of it, an in-group bias was evident, especially in the "values" assigned to the attributes of the in- and out-groups. That is, both groups tended to assign higher values to the attributes that they thought described their in-group's characteristics when compared to the values they assigned to the out-group's attributes. This finding also implies that the principle of metacontrast was effective in forming the participants' perceptions of the members of their out-group.

A particularly noteworthy finding - and one that is especially explicable by SIT - is that the identification with the ingroup is the only variable that explains the significant variance in the difference between the values ratings assigned to one's in- and out-group. In other words, the difference in the participants' scores for their respective in- and out-groups tends to increase the more the members identify with their in-group. The fact that none of the identity styles (personal, social or collective identities) nor the variables of identification with other social groups (gender, family, religion, age group or education) were able to predict a significant variance within these scores means that the nature of the perceptions held by both covered and uncovered university students is governed by in-group identities that are based on the divisions between the two groups of students.

The analyses of the identity dimensions (i.e., "being," "feeling" and "knowing") were informative in describing the content of each group's identity. First of all, it was found that the variables "identification with religion," "identification with the in-group" (the covered students) and "collective identity" were the most decisive in the "being" dimension of the covered participants' identities, whereas the variables "identification with gender group" and "personal identity" occupied a central position in the identities of the uncovered participants. It should be noted that the finding regarding the high predictability of one's group membership from their level of religious group identification corresponds closely with previous findings, and provides further evidence that the issue has to be considered in relation to the variable of religious identification.

The findings regarding the "feeling" dimension, however, yielded a somewhat different picture, indicating that differentiating between the identity dimensions is indeed an effective way of approaching social identities, as the covered and uncovered groups were quite similar in their perceptions and evaluations of fourteen of the fifteen social categories. The "similarity-to-self" ratings of the attributes provided by the students for several categories differed significantly only in the "women in general" category, with the uncovered participants tending to perceive the attributes they had provided for "women in general" as more closely reflecting their own personalities than the covered participants. In the results of the comparison of the "value ratings" that the participants assigned to their attributes, a significant group of differences was found only for the "we, the devout people" and "university students in general" categories. Covered participants evaluated 
devout people in a positive way, whereas their evaluations for "university students in general" were negative. Although the obtained differences are by no means unimportant, the overall similarity between groups is quite striking.

Finally, the findings regarding the "knowing" dimension, which was analyzed by focusing on the perceptions and evaluations about the "ideal woman" category, allowed the content of the prevalent norms (or prototypes) in each group to be understood. The results of the comparisons of the "similarity-to-self" ratings for this category showed that, when compared to uncovered students, the covered students saw the attributes they provided for the "ideal woman" category as more similar to themselves. A closer look at the "value" ratings, however, reveals that the covered and uncovered groups differed very little from each other in terms of the attributes they ascribed to an "ideal woman". This lack of differentiation indicates that these ideals (or prototypes) are similarly important for the members of both groups. An analysis of the actual content of the attributes ascribed to the "ideal woman" category by the respondents provides additional support to the argument that the group members' descriptions of an "ideal woman" reflect their own perceived social role. The ten most frequently used adjectives by the uncovered students when describing their concept of an "ideal woman" were hardworking, successful, honest, financially self-sufficient, giving, good mother, self-sufficient, cultured, free and self-confident, while in contrast, for the covered group, these were giving, affectionate, tidy, educated, respectful, clever, considerate, devout, honest and tolerant. It can be concluded from this data that the covered group's prototype carries a more traditional outlook, and has roots in the assigned role of women in the Islamic tradition. Accordingly, it is apparent that the perceived societal role assigned to women occupies a pivotal position within the headscarf issue.

\section{Implications for Practice}

The findings of this study regarding the individual-level analyses (i.e., the results of multiple regression analyses) showed that identification with the in-group variable is the key to understanding the differential evaluations directed at the individual members of the in- and out-groups, that is, the in-group bias. Previous studies related to SIT have revealed that when threatening sociopolitical events force the individual to perceive the social environment in terms of his/her own social identity rather than their personal identity, the likelihood of identifying with the in-group and evaluating the members of the out-groups in a negatively biased way increases (see, Hogg \& Abrams, 1998). Accordingly, the tension within the Turkish political system can be seen as a decisive factor in preventing a deepening of the conflict between covered and uncovered groups, as this would be likely to result in additional "identity threats" (Branscombe, Ellemers, Spears \& Doosje, 1999) for individuals in both groups in the near future.

The group-level findings of this study have highlighted that, notwithstanding the schism that has been observed in the political arena for almost three decades, covered and uncovered university students exhibit considerable similarities with regard to several social categories (see Table 1). A similar picture arises when the covered and uncovered students' similarity-to-self ratings and the value ratings of the descriptions they provided for different social categories are considered. Although these findings are quite encouraging in terms of finding a common ground for the betterment of the perceptions of these groups, the main difficulty would appear to lie in the different "moral frameworks" that legitimize the presence of women in the public space. A recent longitudinal study on Gordon Allport's (1954) famous "contact hypothesis," which states that contact with the members of out-groups is the most effective way of reducing prejudice, has shown that contact between majority and minority members reduces prejudice, although prejudice also reduces contact under some conditions (Binder, Zagefka, Brown, Funke, Kessler, Mummendey, Maquil, Demoulin \& Leyens, 2009). As seen in the descriptions of the "ideal woman" provided by the participants in this study, the content of these "frameworks," as derived from rather contradictory belief systems (secular and religious), can be regarded as an obstacle in preventing the escalation of conflict. Coordinated efforts to show and persuade both parties that these "rival moral frameworks" do not have to be mutually exclusive, and an inherent threat to one's identity can be effective in enhancing the rights of Turkish women in the near future.

\section{References}

Aldikacti-Marshall, G. (2005). Ideology, progress and dialogue: A comparison of feminist and Islamist women's approaches to the issues of head covering and work in Turkey. Gender \& Society, 19, 104-120.

Allport, G. W. (1954). The nature of prejudice. Cambridge, MA: Addison-Wesley.

Branscombe, N. R., Ellemers, N., Spears, R. \& Doosje, B. (1999). The context and content of social identity threat. In N. Ellemers, R. Spears, \& B. Doosje (eds.) Social identity, context, commitment, content. (pp. 35-58). Oxford: Blackwell.

Bilgin, N. (1995). Sosyal psikolojide yöntem ve pratik çalışmalar [Method and applied studies in social psychology]. Ankara: Sistem Yayıncilık.

Binder, J., Zagefka, H., Brown, R., Funke, F., Kessler, T., Mummendey, A., Maquil, A., Demoulin, S. \& Leyens, J. (2009). Does contact 
reduce prejudice or does prejudice reduce contact? A longitudinal test of the contact hypothesis among majority and minority groups in three European countries. Journal of Personality and Social Psychology, 96, 843-856.

Brown, R. (2000). Social identity theory: Past achievements, current problems, and future challenges. European Journal of Social Psychology, 30, 745-778.

Cheek, J.M. \& Briggs, (1982). Self-consciousness and aspects of identity. Journal of Research in Personality, 16, 401-408.

Coşkun, H. (2004). Kimlik ölçeğinin bir Türk örnekleminde gerçerlik ve güvenirlik çalışması [A reliability and validity study of the Identity Scale in a Turkish sample]. Türk Psikoloji Yazıları [Turkish Psychology Articles], 7, 11-21.

Dumont, K. and Louw, J. (2007). A citation analysis of Henri Tajfel's work on intergroup relations. International Journal of Psychology, 44, 46-59.

Gökarıksel, B. (2009). Beyond the officially sacred: religion, secularism, and the body in the production of subjectivity. Social \& Cultural Geography, 10, 657-674.

Göle, N. (1996). The forbidden modern: Civilization and veiling. Ann Arbor: Univ. of Michigan Press.

Hogg, M.A. \& Abrams, D. (1998). Social identifications: A social psychology of intergroup relations and group processes. London: Routledge.

Hogg, M. A. (2006). Social identity theory. In P. J. Burke (ed.), Contemporary social psychological theories. (pp. 111-136). Stanford, CA: Stanford University Press.

Hortaçsu, N. (2000). Intergroup relations in a changing political context: the case of veiled and unveiled university students in Turkey. European Journal of Social Psychology, 30, 733-744.

Huddy, L. (2004). Contrasting Theoretical Approaches to Intergroup Relations. Political Psychology, 25, 947-967.

Kalaycıoğlu, E. (2005). The mystery of the Türban: Participation or revolt? Turkish Studies, 2, 233-251.

Phinney, J. (1990). Ethnic identity in adolescents and adults: A review of research. Psychological Bulletin, 108, 499-514.

Tajfel, H. (1978). Intergroup behavior: I. Individualistic perspectives. In H. Tajfel \& C. Fraser (Eds.) Introducing Social Psychology. Harmondsworth: Penguin.

Tajfel, H. (1982). Social psychology of intergroup relations. Annual Review of Psychology, 33, 1-39.

Tajfel, H. \& Turner, J. (1979). An integrative theory of intergroup conflict. Reprinted in W. G. Austin \& S. Worchel (eds.), The social psychology of intergroup relations. (pp. 33-47). Monterey, CA: Brooks/Cole.

Turner, J. C. (1999). Some current issues in research on social identity and self-categorization theories. In N. Ellemers, R. Spears, \& B. Doosje (eds.) Social identity, context, commitment, content. (pp. 6-34). Oxford: Blackwell.

Verkuyten, M. (2005). The social psychology of ethnic identity. Hove and New York: Psychology Press.

Wing, A. K. \& Varol, O. O. (2007). Is secularism possible in a majority-Muslim country? The Turkish example. Texas International Law Journal, 4, 1-54. 